Pedagogía y Saberes n. ${ }^{\circ} 55$ Universidad Pedagógica Nacional

Facultad de Educación. 2021. pp. 65-76

\title{
Por uma pedagogia da pergunta em tempos pandêmicos: diálogos freireanos entre coletivos docentes latino-americanos ${ }^{*}$
}

For A Pedagogy of the Question in Pandemic Times: Freirean Dialogues between Latin American Teachers Collectives Para una pedagogía de la pregunta en tiempos pandémicos: diálogos freireanos entre colectivos de profesores latinoamericanos

Mairce da Silva Araújo** Regina Aparecida Correia Trindade ${ }^{* * *}$ Danusa Tederiche Borges de Faria ${ }^{* * * *}$

\section{Para citar este artículo}

da Silva Araújo, M., Correia Trindade, R., y Borges de Faria, D. (2021). Por uma pedagogia da pergunta em tempos pandêmicos: diálogos freireanos entre coletivos docentes latino-americanos. Pedagogía y Saberes, (55). https://doi. org/10.17227/pys.num55-13109

* Este artigo de investigação nasceu como reflexões acerca do Projeto Memória da Quarentena diálogos entre Brasil e Peru, realizado virtualmente pela plataforma Zoom no ano de 2020 entre redes docentes dos respectivos países.

** Faculdade de Formação de Professores/Universidade do Estado do Rio de Janeiro (FFP UERJ). Doutora em Educação. Correio eletrônico: mairce@hotmail.com. Orcid: https://orcid.org/0000-0003-1434-7796

*** Faculdade de Formação de Professores/Universidade do Estado do Rio de Janeiro (FFP UERJ) e Universidade Federal do Rio de Janeiro (UFRJ). Mestra pelo Programa de Pós Graduação em Educação (PPGEdu) da UNIRIO e Doutoranda em Educação pelo Programa de Pós Graduação em Educação Processos Formativos e Desigualdades Sociais (PPGedu FFP/UERJ). Correio eletrônico: ginatrindade@gmail.com. Orcid: https://orcid.org/0000-0001-6787-5029

**** Faculdade de Formação de Professores/Universidade do Estado do Rio de Janeiro (FFP UERJ) e Universidade Federal do Rio de Janeiro (UFRJ). Mestranda em Educação pelo Programa de Pós Graduação em Educação Processos Formativos e Desigualdades Sociais (PPGedu FFP/UERJ). Correio eletrônico: danusa.tederiche@hotmail.com. Orcid: https://orcid. org/0000-0001-7317-8393 


\section{Resumo}

Este artigo de investigação tem como base empírica narrativas de docentes participantes do Projeto Memórias da Quarentena: diálogos entre Brasil e Peru, realizado em 2020, entre coletivos de professores/as brasileiros/as e peruanos/as. As narrativas compartilhadas no projeto sobre as experiências nos/com os tempos pandêmicos, aconteceram por meio de encontros virtuais e foram desencadeadas por uma pergunta problematizadora refletindo sobre o espaçotempo, sobre o pensarfazer docente. Tendo como suporte teóricometodológico reflexões do campo investigativoformativo e dos estudos do/no/com cotidiano, a pesquisa teceu diálogos entre as narrativas docentes e a obra de Paulo Freire, como processo formativo, coletivo e investigativo, problematizando a realidade deste tempo histórico e pandêmico da covid-19.

\section{Palavras-chave}

redes docentes; pandemia; narrativa; processos formativos; pedagogia da pergunta; América Latina

\section{Abstract}

This research article is based on empirical narratives of participating teachers of the Memories of Quarantine Project dialogues between Brazil and Peru, held in 2020, between collectives of Brazillian and Peruvian teachers. The narratives shared in the project about the experiences in/with the pandemic times, happened through virtual encounters and were triggered by a problematizing question reflecting on spacetime, on the thinking of teaching. Having as theoretical-methodological support reflections of the field and studies of daily/with daily life, the research has made dialogues between the teaching narratives and the work of Paulo Freire as a formative, collective and investigative process problematizing the reality of this historical and pandemic time of covid-19.

\section{Keywords}

teaching networks; pandemic; narrative; formative processes; pedagogy of the question; Latin American

\section{Resumen}

Este artículo de investigación se basa en las narrativas de los docentes que participan en el Proyecto Memorias de Cuarentena: diálogos entre Brasil y Perú, realizado en 2020, entre colectivos de profesores/as brasileños/as y peruanos/as. Las narrativas compartidas en el proyecto sobre las experiencias en/con tiempos de pandemia, se llevaron a cabo a través de reuniones virtuales y fueron desencadenadas por una pregunta problemática que reflexiona sobre el espacio-tiempo, sobre el pensar-hacer docente. Teniendo como sustento teórico-metodológico las reflexiones desde el campo investigativo-formativo y estudios de/en/ con lo cotidiano, la investigación tejió diálogos entre las narrativas docentes y la obra de Paulo Freire, como proceso formativo, colectivo e investigativo, problematizando la realidad de esta época histórica y pandémica de la covid-19.

\section{Palabras clave}

redes docentes; pandemia; narrativa; procesos formativos; pedagogía de la pregunta; Latinoamérica 


\section{Introdução}

Das tantas coisas que nos acontecem cotidianamente, o que selecionar para congelar numa escrita, que conte para quem vem depois de nós, a experiência de viver a pandemia?

$92^{1}$ dias,

2.208 horas

132480 minutos,

7948800 segundos dentro de casa

A luta cruel, que atravessa minhas experiências pandêmicas, entre o tempo grego Krónos, das horas, dos compromissos, das obrigações e o tempo Aiós, da intensidade, da experiência, luta que faz com que uma hora possa valer uma eternidade e noventa dias passe num piscar de olhos, me levou ao encontro dos relógios do grande mestre catalão Salvador Dali, um dos símbolo do movimento surrealista, que tem o sugestivo título "A Persistência da Memória".

Debruçar-me sobre o papel em branco, escolher os lápis de cor, esforçar-me para reproduzir a obra de Dali, em busca de traduzir os sentimentos de confinamento, após estar três meses e dois dias dentro de casa, foram movimentos para ajudar a compreender-me, me debruçando sobre uma frase retirada de algum livro, cuja fonte se perdeu na memória: a arte existe porque a vida não basta.

Na obra de Dali, as imagens de três relógios derretidos parecem nos alertar sobre a irrelevância da passagem do tempo e, ao mesmo tempo, a presença de uma mosca sobre um dos relógios lembra-nos que o tempo não pára, ele voa. Contudo, na experiência hoje vivida, tudo se atravessa, tanto o tédio dos dias iguais que parecem eterna repetição, nos remetendo ao passado de nossos avós, quanto à vertigem dos instantes diversos, dilatados, acelerados (De Masi, 2000, p. 200) que caracteriza nossos tempos...

Assim, entre o tédio e a vertigem, o olhar através das janelinhas virtuais, de dentro de casa para o mundo levanta novos questionamentos...

(Registro da docente Mairce Araújo ${ }^{1}$ ).

1 A suspensão das aulas no Estado do Rio de Janeiro (Brasil) aconteceu no dia 13 março 2020. A narrativa docente foi escrita no dia 17 de junho de 2020. Em 20 de dezembro de 2020, quando finalizamos a escrita do presente artigo, somavam-se 279 dias, 6696 horas, 401760 minutos, 24105600 segundos.
0 ano de 2020 foi marcado por uma pandemia, pelo óbito de muitas vidas humanas, pelo isolamento social, pela suspensão das aulas presenciais nas instituições de ensino, que atingiu não somente o Brasil mas diversos países da América Latina ${ }^{2}$, tempo igualmente marcado pelo desafio de imensa complexidade: buscar individual e coletivamente apreender, compreender, ressignificar e problematizar o cotidiano e os modos de pensarfazer (Alves e Garcia, 2012) a vida, os hábitos, as relações com o meio e com o outro em uma (re)configuração dos/nos espaçostempos (Alves, 2010, p. 1211).

$$
\begin{aligned}
& \text { Casa ...lugar de muitos tempos, espaços, cantos, } \\
& \text { passagens } \\
& \text { Casa...caverna...cela... } \\
& \text { Cela...célula...corpo coletivo }
\end{aligned}
$$

Contradições e paradoxos explodem a cada instante: a natureza se abre em vida, enquanto a humanidade se confronta com a morte.

Uma parte da humanidade se isola e protege - e a casa é a trincheira da proteção e do aconchego.

Enquanto outra parte da humanidade, a maior

parte, continua exposta: a falta de políticas

publicas de atendimento à população; o não

atendimento aos direitos básicos: vida, saúde, moradia, água potável, alimentação, segurança, educação, lazer e cultura. A casa pode ser o lugar

do perigo - aumento da violência doméstica...

Amplificando e expondo a crueldade das desigualdades sociais vividas pela humanidade, o coronavírus ameaça matar nossas lutas e esperanças de construir um mundo mais igualitário.

Paulo Freire nos ajuda a pensar: Esta é uma situação-limite?

Existem caminhos para romper com ela?

O educador nos ensina, as situações-limites nos colocam algumas alternativas: ou as percebemos

como um obstáculo que não somos capazes ou não queremos enfrentar e nos acomodamos ou as enfrentamos para romper com elas e inaugurar

2 Como nosso diálogo se estabelecerá com Peru, mencionamos aqui a América Latina, contudo, sabemos que este impacto de deu, mesmo que de formas diferenciadas, em todo planeta.

3 A opção pela escrita aglutinada ou mesmo invertida de algumas palavras afina-se com as justificativas de pesquisadoras/ res do campo dos estudos do cotidiano e justifica-se teoricamente como um exercício de busca de superação da dicotomia provocada por termos, que tratam o pensar e o fazer docente como instâncias separadas. Conferir em: Garcia e Alves (2012). 
um outro possível, em outras palavras extraindo delas o inédito-viável. Para isso, precisamos mais do que nunca entender essas situações-limites em sua profundidade. Elas implicam sempre a existência de quem se beneficia diretamente e serve e alimenta as situações-limites - os dominantes e aqueles/as afetados diretamente por elas - os/as oprimidos/as.

o Projeto Memórias da Quarentena, fortalecendo o diálogo entre docentes latino-americanos/ as foi uma de nossas opções de enfrentar a situação-limite que estamos vivendo e produzir inéditos-viáveis. Onde nos querem divididos/ as e subalternizados/as nos reunimos para compartilhar nossas experiências.

$O$ olha freireano, assim, não nos autoriza a fraquejar diante de tantos obstáculos... ele nos desafia a olhar e a construir, dentro do caos em que vivemos, outro mundo possível, enfrentando o tédio que se apresenta na aparência da repetição dos dias e a vertigem dos acontecimentos

que nos atropelam...

(Registro da docente Mairce. Araujo).

Neste contexto de mudanças profundas e significativas do/no pensarfazer (Alves e Garcia, 2012), fomos provocadas $/ \operatorname{dos}^{4}$ a mergulhar em uma reflexão, problematização sobre nossa percepção dos/nos cotidianos e suas mudanças no cenário pandêmico, compreendendo o cotidiano conforme Garcia (2003, p. 193) como um espaço que "assusta, dá medo, intriga, fascina" que nos desafia a nos revelar em suas dobras que ao se desdobrar deixa aparecer o que estava escondido e à primeira vista não aparecia.

Fomos provocadas/os, a partir da pandemia, a repensar a dimensão do tempo como construção humana e, consequentemente, das relações espaciais que se entrelaçam a este tempo. Passos (2018) amparado na discussão que Paulo Freire tece sobre o tempo, afirma que: "qualquer tempo vivido precisa a-presentear-se como tempo próprio e singular, que se costura na grande ciranda de outros seres semelhantes, cujas temporalidades precisam ser entretecidas numa comunidade de destino e de lutas coletivas." (p. 675).

4 Coerente com o referencial politicoepistêmico que sustenta a obra freireana, também fazemos a opção pelo uso das designações de gênero em busca de reafirmar lógicas e modos de pensar a vida pautados em relações igualitárias entre seres humanos, independente da orientação sexual.
Nestes tempos pandêmicos, o cotidiano que outrora nos era mais rotineiro ${ }^{5}$, conhecido, deu lugar a outras formas de (re)configuração das atividades cotidianas, afetando também as práticas docentes presenciais, que passam a se (re)desenhar em uma dimensão virtual, revelando em suas dobras vivências e experiências outras.

O tempo e suas temporalidades em diálogo com os espaços que os constituem vão sofrendo mudanças em um contexto em que a presencialidade passa a ser ressignificada, diante das limitações impostas pelo isolamento social ${ }^{6}$ em uma prática de virtualidade como resultado da necessidade da interação entre as pessoas.

Esta necessidade suscita desdobramentos e deslocamentos em busca de (com)partilhar, de refletir, de trocar, problematizar, de aprender e apreender, de estar junto mesmo que diante das telas e espaços virtuais. Interação, que em nosso caso abarcou professoras/res brasileiros/as e peruanos/as, participantes de diferentes redes docentes que organizaram o Projeto intitulado Memórias da Quarentena: diálogos entre Brasil e Peru, cujo exercício de pensamento que atravessou os encontros foi o de buscar compreender as repercussões da pandemia em nosso saberfazer docente em diálogo com Paulo Freire. Como Paulo Freire nos ajudaria a compreender este tempo pandêmico e suas repercussões no processo educativo? A pergunta problematizadora, convidou a todas/os a um (re) encontro com o pensamento freireano. Os encontros entre os países foram se estabelecendo mensalmente, trazendo narrativas, textos, poesias, vídeos, dentre outros modos de expressão, compartilhados sobre as temáticas apresentadas e seus des-dobra-mentos.

Este artigo foi elaborado em quatro seções: na primeira, abrimos a discussão sobre as novas configurações espaçotemporais e as possibilidades de produção de um outro pensarfazer docente na pandemia dialogando com Freire. Na segunda seção, contextualizamos o projeto Memórias da Quarentena: diálogos entre Brasil e Peru, bem como os coletivos docentes REDEALE (Brasil) e REDENu, REDIÁlogos (Peru) que o conceberam. Trazemos também como caminho investigativoformativo o diálogo entre pares e reafirmamos

5 A ideia de rotina trazida aqui não deve ser lida como um cotidiano engessado, cristalizado, como se nele não houvesse espaço para surpresas, rupturas, alterações em sua ordem, mas como uma rotina previamente já estabelecida dentro das escolhas individuais de seus sujeitos.

6

Em atendimento às determinações da Organização Mundial da Saúde (oms), cujo entendimento é de que o isolamento social se torna uma ferramenta de enfrentamento ao SARS-2 CoviD19, evitando propagar o contágio e, assim, colapsar os sistemas de saúde. 
assim, a importância do projeto para a produção de uma documentação narrativa (Suárez, 2017), que dê a ver memórias e experiências do magistério do ponto de vista dos/das docentes. Na terceira seção partimos de uma pergunta problematizadora que nos permitiu pensar junto com Freire e as narrativas docentes a potência da pedagogia da pergunta em tempos de pandemia e de isolamento, onde o saberfazer docente tem se dado mediatizado pela tecnologia. Os resultados encontrados no projeto nos levam a reafirmar a relevância da pergunta como chave da construção da criticidade docente e da percepção histórica em movimento e construção. E na quarta e última seção, destacamos a incompletude deste processo, considerando que ainda estamos imersos na pandemia, contexto provocador de tantas outras perguntas a suscitar novas problematizações e diálogos.

\section{Tempos pandêmicos, memória e processos formativos entre redes e coletivos docentes}

A emergência da pandemia e de seus desdobramentos nos insere em uma outra relação dos/nos espaçostempos (Alves, 2010, p. 1211). Diríamos que esta via outra de relação espaçotemporal nos convida a refletir sobre o tempo do pensarfazer docente (Alves e Garcia, 2012) de antes da pandemia e do emergente da/ na pandemia. Para muitas/os de nós o tempo da/na pandemia se constituiu em isolamento, em poucas ou quase nenhuma interação e contato presencial entre as pessoas, sobretudo as do ambiente de trabalho. o tempo, antes repleto de deslocamentos físicos seja para o trabalho, seja para espaços de estudo, seja para outros espaços formativos ou interativos, se vê diante da urgência pandêmica por se reconfigurar. É preciso repensar, diante das possibilidades que se apresentam, outras formas do pensarfazer docente (Alves e Garcia, 2012) e perceber nestes espaços a possibilidade formativa que se apresenta.

\footnotetext{
Mais uma vez os homens, desafiados pela dramaticidade da hora atual, se propõem a si mesmos como problema. Descobrem que pouco sabem de si, de seu "posto no cosmos", e se inquietam em saber mais. Estará, aliás, no reconhecimento do seu pouco saber de si uma das razões desta procura. Ao se instalarem na quase, senão trágica descoberta do seu pouco saber de si, se fazem problema a eles mesmos. Indagam. Respondem, e suas respostas os levam a novas perguntas. (Freire, 2005, p. 31)
}

Seria este tempo pandêmico um tempo em que o saber de si e o saber do outro tornou-se uma necessidade latente de aproximação, de humanização? Uma urgência por estar junto, pensar junto, mesmo que este junto seja em janelas virtuais? Paulo Freire, no tempo histórico de sua escrita já nos indicava que "os homens desafiados pela dramaticidade da hora atual se propõem a si mesmo como problema". Acreditamos que esta afirmação continua atual, e a partir dela pensamos que a dramaticidade imposta pela pandemia, agudizando desigualdades, instaurando incertezas, medos, nos convida a reavaliar nosso "posto no cosmo" e a perceber, fortalecer a dimensão do coletivo neste processo em que a individualização se fez expressiva diante do isolamento social.

Paulo Freire, por meio da narrativa de sua própria experiência, nos fala sobre um Tempo fundante, quer dizer, "um tempo funda e que por isso se abre à profundidade" (2020, p. 201). Acreditamos que a pandemia traz consigo a emergência de profundidades reveladas na agudização das desigualdades, em tantos óbitos, e na reflexão do nosso lugar enquanto espécie no planeta, em contrapartida, também traz a urgência das relações humanas, das trocas, do apoio mútuo e da busca pela compreensão do momento que atravessamos e nos atravessa em uma dimensão coletiva, em diálogo com o outro.

Paulo Freire foi um pensador comprometido com a vida, com a existência humana, trazendo profundas contribuições que nos instrumentalizam a pensar a materialização dessa existência, em sua condição histórica, social e sobretudo coletiva, considera que: "não é no silêncio que os homens se fazem, mas na palavra, no trabalho, na ação-reflexão" (2005, p. 90), e em Freire é por meio da palavra que é possível estabelecer um diálogo, compreendido por ele, como fenômeno humano.

A existência, porque humana, não pode ser muda, silenciosa, nem tampouco pode nutrir-se de falsas palavras, mas de palavras verdadeiras, com que os homens transformam o mundo. Existir, humanamente, é pronunciar o mundo, é modificá-lo. 0 mundo pronunciado, por sua vez, se volta problematizado aos sujeitos pronunciantes, a exigir deles novo pronunciar. (Freire, 2005, p. 90)

Entendemos que pronunciar o mundo não deve ser um ato solitário, pronunciar o mundo por meio da palavra pressupõe o outro, pressupõe um processo comunicativo, uma escuta, onde a palavra é pronunciada, mas também é refletida, e problematizada, e por isso está em movimento, ecoa no outro, ressoa em nós, nos faz um convite ao mergulho reflexivo, que não se esgota quando a palavra finda. Amparadas em Freire, entendemos que dialogar é (com)partilhar, é partilhar com o outro nossas perspectivas, nossas visões de mundo, nossos sonhos, nossos desafios, 
medos, e ao mesmo tempo, sentir na relação dialógica com o outro um movimento latente, formativo, cujas palavras permanecem ali, sendo tecidas, fiadas e ressignificadas em nós e em nossa relação com o outro e com o mundo, afinal "o diálogo é uma exigência existencial" (Freire, 2005, p. 91).

Desta forma, trazer estas palavras, por meio das narrativas, implica pensar a palavra aqui registrada não como algo estático, mas como uma palavra viva, que ressoou em nós nos encontros, e que pode ressoar no outro por meio do convite à partilha que a proposição deste artigo deseja cumprir. Também como uma palavra histórica, que nos remete a vivências em tempos pandêmicos, que nos convida ao exercício de pensar este tempo junto, afinal "se o diálogo é o encontro dos homens [e das mulheres] para ser mais, não pode fazer-se na desesperança." (Freire, 2005, p. 95) e para nós não há maior desesperança que a ausência de diálogo, que a reflexão solitária e esquecida.

Em um texto que Brandão faz para a revista Piranguá do Conselho de Educação Popular da América Latina e do Caribe (CEAAL), salienta a importância do outro em nós, quando afirma que:

Tudo o que pensei, pensamos; tudo o que fiz, fizemos; tudo o que realizei, realizamos; tudo o que vivi, vivemos. Nenhuma ideia, nenhuma prática, nenhuma iniciativa é minha sem haver sido antes, durante e depois... nossa. Entre nós, educadores, todo o "eu" deve encontrar o "nós" que lhe atribui sentido e valor. (2018, p. 117)

Neste sentido, compreender-nos enquanto seres inconclusos, que fazemos na relação com o outro é fundamental no processo de existir e de perceber-se estar sendo no mundo (Freire, 2005), especialmente compreender a história em um movimento complexo de permanências e rupturas e não como algo determinado e engessado. Diante desta experiência formativa, única, em diálogo com o outro, o coletivo ganha dimensões potencializadoras.

\section{Entrelaçando fios e ressignificando memórias entre redes docentes latino-americanas}

A aproximação entre os coletivos docentes REDEALE (Rede de Docentes que Narram sobre Infância, Alfabetização, Leitura e Escrita) do Brasil, REDENU (Red Desenredando Nudos) do Peru teve início em 2015, a partir do interesse das respectivas redes em trocar experiências sobre os seus saberesfazeres docentes, entretanto, a REDIÁLogos do Peru se inseriu nos encontros com interesse também em mobilizar trocas e aprendizagens entre as referidas redes compondo o Projeto Memórias da Quarentena, diálogos entre Brasil e Peru a partir de 2020, no contexto da pandemia.

As interlocuções entre as redes dos dois países foram motivadas pelo desejo de construir parcerias para investigar modos de pensar e praticar ações formativas docentes referendadas pelos princípios de alteridade, da investigação da própria prática e do trabalho em redes de formação, apontando para uma formação mais democrática, comprometida com a construção cotidiana de práticas críticas e dialógicas. Tais encontros, que se caracterizam como espaços instituintes, na medida em que nasceram dos desejos de formação e interlocução entre as/ os próprias/os docentes, grande parte delas/es da escola básica, aconteceram a partir dos Encuentros Iberoamericanos.

O projeto Memórias da Quarentena: diálogos entre Brasil e Peru nasceu no primeiro encontro entre as redes latino-americanas em abril de 2020, no contexto da pandemia provocada pela covid-19, do isolamento social, da suspensão das aulas presenciais, bem como da necessidade de refletir individual e coletivamente sobre este tempo, tão atípico, inesperado e desafiador. A proposição dos encontros trouxe alinhavado, frente à relevância do pensador Paulo Freire em nossa atualidade, a proposta de tecer uma interlocução com seu legado, no sentido de buscar refletir sobre estes tempos pandêmicos e suas repercussões no cotidiano escolar.

Foram realizados um total de seis encontros entre os coletivos, no período de abril a agosto de 2020 , através da plataforma Zoom, com duas horas de duração, nos quais foram produzidas um corpus de 29 narrativas escritas sob o formato de cartas, crônicas, vídeos, poesias, música, desenhos, fotografias, contos, acrósticos, além dos depoimentos orais, que compõem o acervo da investigação e serviu de base para a produção deste artigo.

Colocando-se no campo da investigação narrativa, a pesquisa busca a construção de um conhecimento com as/os docentes, que se configure, tanto como um processo de investigação, quanto um processo de formação.

Nessa perspectiva os encontros proporcionados pelo projeto Memórias da Quarentena diálogos entre Brasil e Peru possibilitaram a seus/suas participantes viverpesquisarnarrarformar (Bragança, 2018, p. 65) o cotidiano em sua pluralidade de olhares, de experiências, de narrativas, potencializando o processo formativo e o processo humanizador. 
O diálogo com as narrativas docentes trazidas no artigo em tela confirma, a nosso ver, a potência da dimensão formativa que acontece nas relações coletivas.

Maria Isabel Gutiérrez, docente pertencente à rede peruana REDENU, afirma, "para las redes peruanas, memorias de cuarentena, hay un significado, un pretexto para unirnos, convocarnos a reflexionar juntos, plantearnos una tarea, creo que lo más grande es unirnos a las redes que hemos aprendido a formar comunidad".

Gutiérrez defende que fazer parte de redes e coletivos docentes que narram, discutem e escrevem sobre suas práticas favorece um exercício de reflexão entre nós mesmos e com o outro. Pensamos ainda que ao ampliarmos esta reflexão envolvendo diferentes países a experiência formativa provoca um deslocamento ainda maior, nos convidando a uma relação com outras formas de existir e relacionar com o mundo, com outras culturas, com outros olhares, e com outras experiências e (re)existências.

Narrar e documentar a própria prática docente nos encontros entre redes, se caracteriza assim como uma ação formativoinvestigativa que cumpre um papel político relevante, na medida em que, como alerta Suárez, existe na América Latina uma "memória pedagógica silenciada", que prevalece nos discursos oficiais, "en el lenguaje técnico, pretendidamente objetivo, neutral, desafectado de subjetividad, que imponen las modalidades dominantes de gobierno educativo" (2017, p. 194).

Suárez enfatizando a importância da escrita docente sobre a própria prática, afirma que "Cuando escriben, dan a leer, conversan y re-escriben sus relatos de experiencia los docentes de la documentación narrativa descubren sentidos pedagógicos parcialmente ocultos o ignorados..." (2017, p. 199). Ainda para o autor:

En la medida en que consiguen distanciarse de su práctica para tornarla objeto de pensamiento y discurso, para hacerla material de escritura, lectura e interpretación pedagógica, en la medida en que pueden documentar algunos de sus aspectos "no documentados" o invisibilizados, los docentes narradores se dan cuenta de lo que saben, de lo que no conocen, de lo que no pueden nombrar y de lo que pueden hacer. Ponen en tensión su sabiduría práctica, la componen y recomponen, la objetivan, la fijan en escritura, la leen, la comunican, la critican (Suárez, 2010). Por eso, en el movimiento de "dar a leer" sus relatos pedagógicos, los docentes narradores entregan sus propias lecturas acerca de lo que pasó en la escuela y lo que les pasó como docentes, educadores, pedagogos. (Suárez, 2017, p. 199)
Consideramos, amparadas no pensamento de Suárez, que o projeto Memórias da Quarentena: diálogos entre Brasil e Peru igualmente contribuiu para uma produção documental sobre o pensarfazer docente poética, sensível, crítica, sofrida e artística, dando a ver aspectos do cotidiano escolar que fogem ao escopo de um fazer pedagógico inserido numa rotina burocratizada e, portanto, muitas vezes invisibilizados nestes contextos.

As narrativas das/dos professores sobre suas experiências pessoaisprofissionais, durante o período pandêmico, se apresentaram para nós como memórias fragmentárias que expressam um modo de viver, escrever e guardar a história, compondo um mosaico de memórias e de esquecimentos do tempo vivido. Nesse sentido, tais memórias promovem um alargamento do presente. Buscamos contribuir, assim, para a invenção "de formas memória e de narração, capazes de sustentar uma relação crítica com a transmissão do passado, com o lembrar, e com a construção do futuro e o esperar" (Gagnebin, 2014, p. 221).

Entendemos o conjunto das narrativas compartilhadas no projeto como miscelâneas, fragmentos, anotações de diferentes esferas, ou seja, uma coleção que compõe um mosaico dos tempos que vivemos, aproximando-nos das reflexões de Achilles e Gondar sobre as características do pensamento benjaminiano:

Ao acessarmos o índice das obras de Benjamin percebemos que elas são constituídas por um conjunto de temas diversos, principalmente em 'Rua de mão única', que poderiam ser classificadas como miscelâneas. Isto porque reúnem anotações de diferentes esferas (políticas, sociais, culturais, econômicas, estéticas, filosóficas, literárias, entre outras). Neste universo de fragmentos, gostaríamos de marcar dois importantes termos: 'coleção' e 'experiência'. Arriscamo-nos a dizer que toda coleção composta por esses fragmentos, ruínas, restos ou cacos diversos formam um mosaico que possuem um sentido, expressando algo que está em nível de compreensão que, a princípio, nos passa despercebida. Assim, a cada leitura que fazemos desses textos é possível extrair um olhar, uma imagem e entendimento diferente. (2017, pp. 181-182)

Neste sentido consideramos que documentação narrativa produzida no escopo do projeto nos ajudam a compor uma memória social, política, educativa, pedagógica do tempo presente, memória esta que articula em diálogo com dois países da América-latina: Brasil e Peru, compreendendo as peculiaridades de seus territórios diversos e culturalmente plurais, bem como das práticas diferenciadas, contextos políticos, econômicos e culturais múltiplos. 


\section{A pedagogia da pergunta e os tempos pandêmicos em diálogo com Freire}

Paulo Freire nos convida a refletir sobre a palavra enfatizando que "não há palavra verdadeira que não seja práxis" (2005, p. 89). Compreendemos o potencial problematizador da palavra em um diálogo, e neste sentido a importância da pergunta enquanto chave problematizadora do mundo, da existência, das condições de opressão, enquanto chave para a busca do ser mais, da consciência e da criticidade.

O projeto Memórias da Quarentena: diálogos entre Brasil e Peru nasceu de uma pergunta problematizadora que mobilizou às/aos sujeitos participantes das redes latino-americanas a buscar respondê-la, mas não somente para cumprir uma tarefa, mas sim, mobilizadas/os por este convite a (re)pensar o contexto histórico, social, político, formativo, profissional em uma dimensão temporal e em um movimento individual e coletivo.

0 movimento de refletir sobre o pensarfazer a partir de uma pergunta problematizadora que remetia ao legado de Freire, denotava os dois sentidos que o termo "problematização" abarca em sua obra, segundo Mühl (2018): um sentido epistemológico e o outro antropológico ou ontológico. Como sentido epistemológico, podemos pensar na relação entre sujeito e objeto compreendendo que não há diferenciação entre tais especificidades, uma vez que o sujeito da investigação reflete sobre sua prática, esta problematizada em um contexto histórico, social, temporal, pois conforme pontuou Freire "[...] o conhecimento se constitui nas relações homem-mundo, relações de transformação, e se aperfeiçoa na problematização crítica destas relações" (Freire, 1977, p. 36)." Como sentido ontológico destacamos o conceito freireano de "ser mais" (Freire, 2005), na busca pela superação da dimensão de incompletude, inacabamento e imperfeição, a partir da consciência de ser e estar no mundo.

A pergunta: Como Paulo Freire nos ajudaria a pensar sobre os processos educativos na pandemia? nos convidava a (re)encontrar com seu pensamento, seu legado, suas contribuições que permanecem atuais, tanto no Brasil quanto no Peru, uma vez que as condições de opressão e desigualdades provocadas pelo capitalismo se mantém nestes países e inclusive se agudizam em tempos pandêmicos. ${ }^{7}$

7 A questão do aumento do desemprego é um dos sinalizadores do agudizamento das condições de opressão e desigualdades: em abril de 2020, segundo Institutos de Estudos Peruanos, "cerca de $30 \%$ dos trabalhadores peruanos estavam desem-
Para a professora peruana María Elizabeth Chang: "Paulo nos habla de una pedagogia de la pregunta en el que nuestro estudiante esté en constante diálogo con sus compañeros, con el docente, con sus familia y amigos." e ao elaborar uma reflexão sobre a pedagogia da pergunta em tempos pandêmicos afirma que:

\begin{abstract}
Nosotros como docentes nos estamos dando cuenta que muchos de nuestros estudiantes los conocemos por un nombre y apellido, no tenemos idea de cómo son, lo que piensan, lo que sienten, muchos de nosotros maestros, padres de familia y estudiantes no expresamos nuestros sentimientos y nos enfocamos en el desarrollo de sobrevivir en esta pandemia. Me pregunto qué diría Paulo Freire en esta situación, me imagino que su respuesta sería: estamos dialogando con los estudiantes, conocemos sus intereses, sus necesidades sus expectativas, lo que piensan de lo que están viviendo e cómo lo están viviendo; Paulo nos diría busquemos junto con los estudiantes la verdad de cómo nos encontramos, que dialoguemos como base en la preguntas para lograr descubrir la sabiduría partiendo de la ignorando de conocer lo desconocido, de aprender del día a día, de aprender del sabio de la comunidad, de dialogar constantemente, algunos dirían pero dialogar con quienes en este entorno en el que nos encontramos, podemos utilizar algunos medios como es el caso de las tecnologías de la información, para poder establecer reuniones virtuales y poner sobre la mesa todas nuestras dudas y promover el riesgo y la aventura por aprender a conocer primero a nosotros mismos y luego a los demás, y que tratemos de aprender a desaprender y que nosotros los docentes no somos los que sabemos todo, sino por el contrario que todos podemos aprender de todos, porque estamos en un mundo de constantes aprendizajes sobre todo en contacto uy en relación con nuestra naturaleza. (Narrativa da professora peruana María Elizabeth Chang no encontro de 28/08/2020)
\end{abstract}

A fala da professora Chang comporta diversos elementos que nos convidam a refletir sobre a necessidade de romper com uma prática educativa esvaziada de sentidos, cuja relação entre os sujeitos está centrada nos processos de transmissão de conhecimentos apenas e não na relação e interação entre eles, de suas emoções, de seus sentimentos, de como estão

pregados", (Recuperado 20 de dez de 2020) https://veja.abril. com.br/mundo/covid-19-mais-de-167-000-pessoas-no-peruquerem-deixar-os-centros-urbanos/ Em 23 de out de 2020, o Brasil atingia um número recorde de desempregados, registrando um aumento, em cinco meses, de mais 34 milhões de pessoas desempregadas.https://g1.globo.com/economia/ noticia/2020/10/23/no-de-desempregados-diante-da-pandemia-aumentou-em-34-milhoes-em-cinco-meses-aponta-ibge. ghtml (Recuperado 20 de dez de 2020) 
reagindo neste processo de isolamento social e diante de perdas de entes e familiares, dentre tantos outros aspectos que se desdobram a partir da alteração na rotina da população com o fechamento das escolas.

A professora Amanda Pestana do Brasil também traz sua palavra carregada de uma percepção da escola que antes da pandemia era preenchida pelas presenças, sons, contatos, interações, sensações e agora está vazia: "na escola, apenas carteiras vazias e um estojo esquecido pela abrupta suspensão das aulas. No parque, não há vai e vem dos brinquedos e nem o eco das risadas crianceiras competindo com as buzinas dos carros."

Paulo Freire foi um pensador que se debruçou a pensar nas condições materiais da existência humana, suas relações e construções, mas, mais que refletir se posicionou criticamente, ética e politicamente em defesa dos esfarrapados do mundo e em denúncia às condições de opressão. Neste sentido, defendeu a viabilidade da luta pela humanização como uma possibilidade frente à consciência dos homens de sua própria desumanização, na percepção de sua exploração, opressão.

Esta percepção, esta tomada de consciência, não deve ser compreendida dissociada do entendimento da história e do tempo presente como uma construção humana, e por isso, passível de mudanças, da construção de outros rumos, de outras histórias, e não como algo determinado, cristalizado e impossível modificar. Nos afirmou Freire: "Daí que insisto tanto na problematização do futuro e recuse sua inexorabilidade" (1997, p. 59).

Interessa-nos trazer esta dimensão da percepção da história como possibilidade, como construção, rompendo com qualquer posição fatalista diante da história e dos fatos. Paulo Freire defendia que não podemos perder de vista que toda realidade está aí submetida à possibilidade de nossa intervenção nela, ou seja 'em minha visão, 'ser' no mundo significa transformar e retransformar o mundo, e não adaptar-se a ele" (Freire, 2020, p. 50). E sem dúvida, esta mudança, esta transformação requer uma mudança de olhar para o mundo, de perceber-se pertencente nele, de lançar mão de perguntas a ele, perguntas que não estejam impregnadas de juízos de valor, de respostas prontas, mas de perguntas que possam nos levar a perceber outras possibilidades de leituras, e sobretudo perguntas que possam ser com-partilhadas, refletidas em todo potencial que o coletivo traz.

Neste sentido, María Elizabeth Chang pondera:

Aspectos que consideraría de Paulo en esta pandemia es lo limitar al estudiante ni al docente en la generación de la curiosidad por aprender, el que se genere preguntas constantemente del porqué, el para qué, el cómo, el cuándo, el donde, el con qué y el para qué estoy aprendiendo para enseñar para aprender y aprender a preguntar teniendo en cuenta que el niño desde que nace hace preguntas y con el pasar de los tiempos de olvida de formular sus preguntas porque no encuentra respuestas a dichas preguntas.

Recordemos que nosotros los maestros no tenemos la verdad absoluta y que también tenemos que ser humildes de reconocer que estamos aprendiendo y sobre todo en esta nueva modalidad de la virtualidad, estamos aprendiendo el o uso de diversos dispositivos y medios virtuales para poder relacionarnos virtualmente entre docentes amigos y estudiantes. (Narrativa da professora peruana María Elizabeth Chang no encontro de 28/08/2020)

0 contexto da pandemia se inicia e com ele muitas perguntas são lançadas, no sentido de buscar respostas frente à tantas incertezas, a tantas perdas humanas, a agudização da desigualdade, o desemprego, aos conflitos instaurados pela ordem capitalista onde o lucro prevalece frente às vidas humanas, e, sobretudo dúvidas relacionadas ao que fazer pedagógico que se torna possível neste momento? Quando retornarão as aulas presenciais? Como será possível estabelecer relações de ensino pela via remota? Quantas perguntas foram feitas para saber como usar plataformas digitais, tais como a Zoom utilizada também para os encontros entre as/os docentes envolvidas/os no projeto Memórias da Quarentena: diálogos entre Brasil e Peru.

El hacer en esta pandemia una experiencia de aprendizaje; de aprender y formularme preguntas de buscar generar la curiosidad tanto en los estudiantes como en los colegas maestros, el estar en un constante diálogo de aprendizaje mutuo em libertad para indagar, investigar, y vivir sabiendo conocer sus emociones y sentimientos; es de aprender a vivir la pregunta; vivir la investigación, vivir la curiosidad y conocer su experiencia de aprendizaje del estudiante. (Narrativa da professora peruana María Elizabeth Chang no encontro de 28/08/2020)

Chang chama a atenção para a necessidade de praticar uma pedagogia da pergunta, baseada nos pressupostos freireanos, em oposição à uma prática de transmissão de conhecimento, sem uma preocupação com o que os sujeitos, estudantes e comunidades pensam sobre a pandemia. Para Chang, Paulo Freire, diante deste tempo, nos convidaria a praticar uma pedagogia da pergunta e a incentivar a pergunta como uma curiosidade e uma investigação inerente ao processo de aprender e apreender este tempo, e a partir da pergunta se estabelecer e praticar uma educação 
dialógica. Não existe pergunta errada ou certa, e uma pergunta pode desencadear várias outras. Segundo Chang, a pedagogia da pergunta se constitui um processo formativo e educativo para compreender e aprender os atravessamentos da pandemia.

Freire, nos afirma que:

Estou certo, porém, de que é preciso deixar claro, mais uma vez, que a nossa preocupação pela pergunta, em torno da pergunta, não pode ficar apenas a nível da pergunta pela pergunta. 0 importante, sobretudo, é ligar, sempre que possível, a pergunta e a resposta a ações que foram praticadas ou a ações que podem vir a ser praticadas ou refeitas. Eu não sei se fica claro o que digo. Parece-me fundamental esclarecer que a tua defesa e a minha, do ato de perguntar, de maneira nenhuma tornam a pergunta como um jogo intelectualista. Pelo contrário, o necessário é que o educando, ao perguntar sobre um fato, tenha na resposta uma explicação do fato e não a descrição pura das palavras ligadas ao fato. É preciso que o educando vá descobrindo a relação dinâmica, forte, viva, entre palavra e ação, entre palavra-ação-reflexão. Aproveitando-se, então, exemplos concretos da própria experiência dos alunos durante uma manhã de trabalho dentro da escola, no caso de uma escola de crianças, estimulá-los a fazer perguntas em torno da sua própria prática e as respostas, então, envolveriam a ação que provocou a pergunta. Agir, falar, conhecer estariam juntos. (1985, p. 26)

O movimento de compreensão crítica do mundo nasce de uma curiosidade, de uma pergunta, pergunta que é pedagógica e é política, pois tende sempre a nos ensinar algo, ensinar não somente a quem pergunta, mas também em quem articulado com a pergunta busca encontrar respostas e ou a partir das perguntas se elaborem outras novas.

Caminhando para o fechamento do nosso artigo, entendemos que os resultados do projeto Memórias da Quarentena: diálogos entre Brasil e Peru que nasceu de uma pergunta, desafiadora, problematizadora, cujo exercício de buscar respondê-la, demandou um esforço de pensamento, mas também de planejamento de ações práticas que mobilizem o próprio saberfazer, não podem ser pensados numa perspectiva quantitativa ou mensurável, mas sim nas pistas que as narrativas podem nos trazer na construção de um educação humanizadora.

As problematizações acerca das relações humanas, do fazer docente na pandemia entre os diferentes países trouxeram percepções que nos aproximam enquanto sujeitos históricos em um tempo cuja produção da existência se dá por meio do sistema capitalista, onde condições de opressão, exploração são condições inerentes à própria existência deste sistema. Desta forma, no contexto da pandemia, foi possível perceber que tanto no Brasil quanto no Peru houve uma adesão à prática do ensino remoto, sem que antes se tenha lançado mão de perguntas acerca de seus desdobramentos. A necessidade do isolamento social colocava a via tecnológica como uma opção segura, contudo, há que se considerar desdobramentos sinalizados por ambos os países, tais como: exaustão docente em frente as telas ; a incerteza de que há de fato o alcance real entre as comunidades educativas; o desejo de construir laços e produzir conhecimentos que sejam efetivamente significativos no contexto da pandemia, onde em muitas famílias houve perdas em razão da Covid-19. Outra pergunta lançada foi acerca da perspectiva de educação que se instaura por detrás das telas: estariam os docentes atuando em uma perspectiva de educação bancária, racionalista, fragmentária? Ou seria possível, mesmo diante das limitações postas pela pandemia, estabelecer uma educação problematizadora, emancipatória?

Trazemos estas questões em forma de indagações, pois compreendemos que elas nos convidam a problematizar o saberfazer docente, a lançar mão de perguntas sobre este saberfazer na pandemia, rompendo com uma visão naturalizada, cristalizada de um fazer pedagógico apenas como um ato transmissor de conhecimentos, em uma perspectiva epistemológica racionalista. Que conhecimentos se fazem urgentes na pandemia? Como o exercício da pedagogia da pergunta freireana nos ajuda a pensar na função social, política, estética da escola no contexto pandêmico, e ainda mais, em uma perspectiva emancipatória, tanto do docente enquanto sujeito em um processo constitutivo e formativo, quanto dos estudantes em um movimento reflexivo sobre este tempo? De que forma esta perspectiva de educação freireana torna as experiências brasileiras e peruanas semelhantes apesar de toda diversidade geográfica, política, econômica e social?

Há que se ponderar que ainda estamos imersos na pandemia, desta forma, muitas perguntas ainda persistem e acreditamos que ainda persistirão por um bom tempo mesmo após ter findado esse tempo, e trazemos aqui, defendendo a perspectiva da incompletude freireana, que um dos resultados percebidos na dimensão da pedagogia da pergunta entre as redes docentes do Brasil e Peru está justamente na percepção da importância do exercício da pergunta, da dúvida, da criticidade, da indagação acerca do fazer pedagógico (sem buscar aqui esgotar respostas), que não está dado, não deve ser visto como naturalizado e um ato repetitivo, bancário.

8 Para maior aprofundamento sobre a atuação docente em tempos de pandemia, consultar: Araújo, Oliveira e Trindade (2021) 


\section{(In)conclusões e as perguntas do caminho}

Sonhar não é apenas um ato político necessário, mas também uma conotação da forma histórico-social de estar sendo de mulheres e homens. Faz parte da natureza humana que, dentro da história, se acha em permanente processo de tornar-se... Não há mudança sem sonho como não há sonho sem esperança... (Freire, 1992, pp. 91-92)

Ratificamos em Paulo Freire a percepção do sonho como um processo coletivo, existencial e, portanto, humano. Como diria Morais, (2012, p. 58) olhar o coletivo como forma de caminhar acompanhado.

Pensamos aqui que é preciso construirmos em tempos tão duros, de desigualdades, perdas humanas, desempregos, fome, miséria, mais sonhos que se sonham juntos, mais possibilidades de refletir sobre a realidade com o outro, em um movimento de empatia e acolhimento, em um movimento amoroso que defendeu Freire.

Compreendemos, desta forma, que este processo coletivo de problematizar os cotidianos, em uma dimensão de espaçotempo e de pensarfazer reconfigurados na pandemia em diálogo com o legado de Paulo Freire proporcionou às redes de coletivos docentes que pensam, narram e escrevem sobre suas práticas viverpesquisarnarrarformar (Bragança, 2018) em uma perspectiva humanizadora, dialógica, problematizadora. Possibilitou também a percepção da experiência como conceito benjaminiano em uma dimensão de sentido imbricado em um tempo e uma memória histórica, que por sua vez, produz, através das escritas, uma documentação narrativa (Suárez, 2017).

Defendemos a pergunta como chave investigativa, curiosa, problematizadora, pedagógica, como feita de palavra(s) que pronuncia(m) o mundo, que nos indagam sobre nosso lugar no cosmos, que em tempos pandêmicos nos sacode a perceber a história como possibilidade, como um processo complexo de permanências e rupturas, como resultado de uma construção humana, e por isso, passível de ser mudada.

Acreditamos na palavra pronunciada não somente como convite à pergunta, mas também como convite ao diálogo, por compreender o diálogo como uma necessidade humana de expressar-se, de interagir com o outro, que está intimamente relacionado com $o$ ato de perguntar.

Finalizamos este artigo, destacando o quanto o projeto Memórias da Quarentena: diálogos entre Brasil e Peru, compartilhado entre as redes docentes REDEALE do Brasil, REDENU e REDIÁLOgos do Peru, que teve início a partir de uma pergunta, que convidou a todas e todos a mergulhar em um diálogo com Freire tornou-se um processo formativo, investigativo, dialógico e o quanto nos permitiu perceber o cotidiano em suas dobras, em suas brechas, como espaços tensionados, híbridos, desafiadores, vivos, latentes e potentes territórios formativos.

\section{Referências}

Achilles, D. e Gondar, J. (2017). A memória sob a perspectiva da experiência. Revista Morpheus - Estudos Interdisciplinares em Memória Social, 9(16), 174-196

Alves, N. (2010). Compreensão de políticas públicas nas pesquisas com os cotidianos: para além dos processos de regulação. Educação \& Sociedade, 31(113), 1195-1212.

Alves, N. e Garcia, R. L. (2012). Sobre a formação de professores e professoras: questões curriculares. Em J. C. Libâneo et al. Temas de pedagogia: diálogos entre didática e currículo. Cortez.

Araújo, M, Oliveira, D e Trindade, R. (2021). A atualidade de Paulo Freire em tempos de pandemia: tecendo diálogos sobre os desafios da educação e do fazer docente. Práxis Educativa, 16, (e2116610), 1-20. https://doi. org/10.5212/PraxEduc.v.16.16610.009

Brandão, C. R. (2018). A Educação Popular e o CEAAL na linha do tempo memórias e reflexões de um educador dos anos sessenta Em R. E. López. Estratégias Políticas para Democratizar el Conocimiento: investigación acción participativa, sistematizacíon de experiencias y educación popular, (pp. 116-129). La Pirágua.

Bragança, I. F. S. (2018). Pesquisaformação narrativa (auto) biográfica: trajetórias e tessituras teórico-metodológicas. Em M. H Abrahão et al. Pesquisa (auto) biográfica: diálogos epistêmico-metodológicos. CRV.

Faria, D. T. B. (2021). Experiências Formativas entre professores/as de redes e coletivos docentes latino-americanos. [Dissertação de Mestrado. Universidade do Estado do Rio de Janeiro].

Freire, P. (1977). Extensão ou comunicação? Paz e Terra.

Freire, P. (1992). Pedagogia da Esperança. Paz e Terra.

Freire, P. (1997). Pedagogia da autonomia; saberes necessários à prática educativa. Paz e Terra.

Freire, P. (2005). Pedagogia do Oprimido. Paz e Terra.

Freire, P. (2020). Pedagogia dos sonhos possíveis. Paz e Terra.

Freire, P e Faundez, A. (1985). Por uma Pedagogia da Pergunta. Paz e Terra.

Gagnebin, J. M. (2014). Limiar, aura e rememoração: ensaios sobre Walter Benjamin. Ed. 34. 
Garcia, R. L. (2003). Método, Métodos, Contramétodo. Cortez.

Garcia, R. e Alves, N. (2012). Sobre a formação de professores e professoras: questões curriculares. Em J. C. Libâneo e N. Alves. Temas de pedagogia: diálogos entre didática e currículo. Cortez.

Morais, J. F. S. (2012). Brasil y Perú: cartas para la transformación docente em lenguaje. Em x Taller Latinoamericano pata la Transformación de la Formación Docente em Lenguaje.
Mühl, E. H. (2018). Problematização. Em: D. R. Streck, et al. Dicionário Paulo Freire. Autêntica Editora.

Passos, L. A. (2018). Tempo. Em D. R. Streck, et al. Dicionário Paulo Freire. Autêntica Editora.

Suárez, D. H. (2017). Relatar la experiencia docente. La documentación narrativa del mundo escolar. Revista Teias, 18(50), 193-209. https://doi.org/10.12957/ teias. 2017.30500 